\title{
A thermomechanical model for the analysis of disc brake using the finite element method in frictional contact
}

\author{
Ali Belhocine* and Oday Ibraheem Abdullah** \\ * Department of Mechanical Engineering, University of Sciences and the Technology of Oran, L.P 1505 El -Mnaouer, Oran, Algeria \\ ** System Technologies and Mechanical Design Methodology Hamburg University of Technology, Hamburg, Germany \\ *Corresponding Author: belhocine.2018@gmail.com
}

Submitted : 17/08/2019

Revised :09/08/2021

Accepted : 19/08/2021

\begin{abstract}
In this work, numerical simulations of the transient thermal and the static structural analysis were performed sequentially with the coupled thermostructural method. The numerical procedure of calculation relies on important steps such that the CFD thermal analysis is well illustrated in 3D, showing the effects of heat distribution over the brake disc. Three different brake disc materials were selected in this simulation, and a comparative analysis of the results was conducted in order to derive the one with the best thermal behavior. Finally, the resolution of the coupled thermomechanical model allows us to visualize other important results of this research such as the deformations, the equivalent Von Mises stress of the disc, and the contact pressure of the brake pads. Following our analysis and the results we draw from it, we derive several conclusions. The choice allowed us to deliver the best suitable brake rotor to ensure and guarantee the good braking performance of vehicles.
\end{abstract}

Keywords: Automotive; Brakes; Thermal Conductivity; Thermal Analysis, Friction; Contact.

\section{INTRODUCTION}

Automobile is a complex integration of electronic and mechanical components. One of the major components is the braking system, which is limited due to its shortcomings. In recent years, the simulations based on the finite element method have been used by many researchers to solve countless engineering design problems (Eyercioglu and Y1lmaz, 2021; Sivandi-Pour et al. (2020); Sen et al. (2020); Wang and Ding, 2020; Noufid and Belattar, 2019; Li and Liu ,2018). Several authors (Belhocine and Nouby, 2016; Ishak et al. (2018); Yildiz and Duzgun, 2010; Duzgun, 2012) have performed numerical simulations on disc brake assembly using the finite element method. Choi and Lee $(2003,2004)$ combined the force equilibrium equation and the heat conduction equation to solve the problem and analyzed the transient thermoelastic instability of the disc brake. Hwang and Wu (2010) have studied on 3D thermomechanical coupling model of temperature and thermal stress in a ventilated disc brake. Han et al. (2018) analyzed thermal fatigue stress of automotive brake discs by using the coupled thermomechanical finite element (FE) simulation. Han et al. (2017) presented a three-dimensional finite element (FE) model of a brake system for numerical simulation in which a coupled thermomechanical analysis is carried out to confirm the 
nonuniform contact pressure distribution. Dufrénoy and Weichert (1995) implemented a two-dimensional (2D) fully coupled thermomechanical algorithm taking wear into account. Kao et al. (2000) developed a threedimensional (3D) FE model that can perform fully coupled thermomechanical analysis. They took the effect of wear on contact pressure distribution into consideration. They used this model to study hot judder in a disc brake.

The main purpose of this scientific contribution is to present a numerical simulation of the thermomechanical process during the braking stop in order to show the behavior of the brake disc in contact with the brake pads. From this analysis, more comprehensive result of the disc simulation can be found. Deformations, Von Mises stress distribution of the disc brake assembly, contact pressure distribution of the inner pads, the effect of the grooved brake pad, and the brake caliper type on the stress values are investigated by thermomechanical coupling analysis. Thus, this study provides an effective reference for the design and engineering application of the brake disc and brake pad.

\section{CFD MODELLING AND ANALYSIS WITH ANSYS CFX}

\section{Heat flux entering the disc}

The general formula for calculating the initial flux entering the automotive brake disc can be expressed as follows (Reimpel, 1998):

$$
q_{0}=\frac{1-\phi}{2} \frac{m g v_{0} z}{2 A_{d} \varepsilon_{p}}
$$

where $\mathrm{g}$ is the acceleration of gravity $(9.81)\left[\mathrm{ms}^{-2}\right], a$ is the deceleration of the automobile $\left[\mathrm{ms}^{-2}\right]$, and $z=a / g$ is the braking efficiency.

\section{Boundary conditions and computational details}

CFD model developed in ANSYS CFX used in the search for exchange coefficient values (h) is well shown in Figure 1.

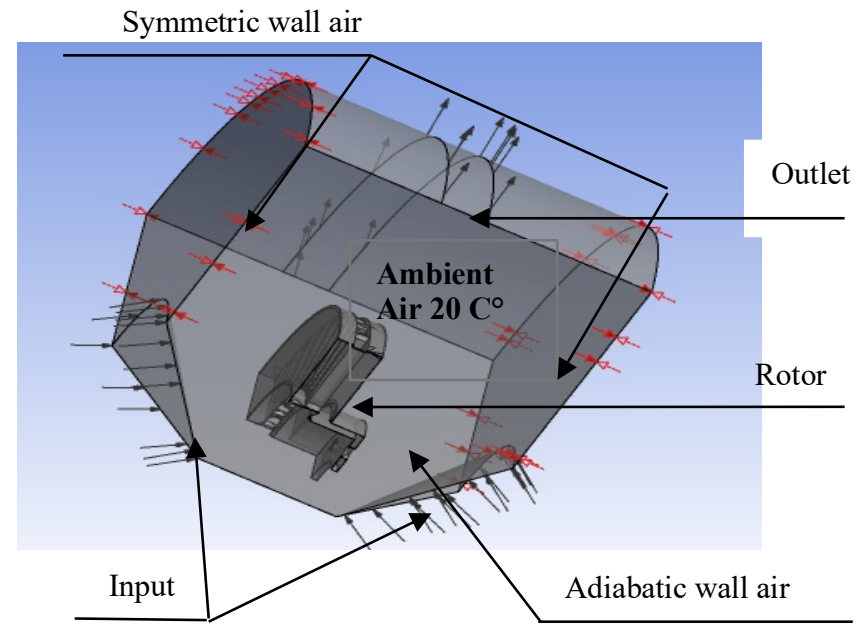

Figure 1. CFD model of ventilated disc brake. 


\section{FINITE-ELEMENT MODELLING}

\section{Modelling Assumptions}

Table 1 lists all the physical parameters and the geometric dimensions of the brake disc used in numerical calculations.

The disc brake is made of gray cast iron (FG15) and the brake pad in isotropic material whose details of properties are presented in Table 2

Table 1. Design parameters of the brake disc.

\begin{tabular}{|c|c|}
\hline Parameter & Value \\
\hline Inside diameter of the disc, $\mathrm{mm}$ & 66 \\
\hline Outside diameter of the disc, $\mathrm{mm}$ & 262 \\
\hline Disc thickness $(\mathrm{TH}), \mathrm{mm}$ & 29 \\
\hline Disc height $(\mathrm{H}), \mathrm{mm}$ & 51 \\
\hline Weight of the car $m, \mathrm{~kg}$ & 1385 \\
\hline Initial velocity $v 0, \mathrm{~m} / \mathrm{s}$ & 28 \\
\hline Deceleration $a, \mathrm{~m} / \mathrm{s}^{2}$ & 8 \\
\hline Time of braking $t_{b}, s$ & 3.5 \\
\hline Effective disc radius $R_{\text {disc }}, \mathrm{mm}$ & 100.5 \\
\hline Ratio braking forces distribution $\phi, \%$ & 20 \\
\hline Factor of disc charge distribution $\varepsilon_{p}$ & 0.5 \\
\hline Disc's swept area $A_{d}, \mathrm{~mm}^{2}$ & 35993 \\
\hline
\end{tabular}

Table 2. Properties of the disc and pad.

\begin{tabular}{|c|c|c|}
\hline Material Properties & Disc & Pad \\
\hline Thermal conductivity, $k\left(\mathrm{~W} / \mathrm{m}^{\circ} \mathrm{C}\right)$ & 57 & 5 \\
\hline Volumetric mass density, $\left(\mathrm{kg} / \mathrm{m}^{3}\right)$ & 7250 & 1400 \\
\hline Specific heat capacity, $c\left(\mathrm{~J} / \mathrm{Kg} .{ }^{\circ} \mathrm{C}\right)$ & 460 & 1000 \\
\hline Poisson's ratio, & 0.28 & 0.25 \\
\hline Friction coefficient, $\mu$ & 0.2 & 0.2 \\
\hline Young modulus, $E(\mathrm{GPa})$ & 138 & 1 \\
\hline
\end{tabular}




\section{EXPERIMENTAL SETUP}

The numerical results of the thermal simulation obtained in this work using ANSYS are validated using the results of the work of Stephens (2006), which was an experimental investigation on temperature distribution of ventilated disc brake rotor. The temperature measurement was conducted using $\mathrm{Cu}$ thermocouples integrated into the disc brake rotors according to VDA285-1, which became accredited until the year 1996, at the mean friction radius as shown in Figure 2(a). The temperature pot-side was measured also by Cu-embedded thermocouple as shown in Figure 2(b). The thermocouples have a cylindrical shape in this case with the sizes $\varnothing=3 \mathrm{~mm}$ and $\mathrm{h}=3$ $\mathrm{mm}$ as in Figure 2(c). The connecting wires were insulated on the brake-rotor-side and were connected to the signal amplifier.

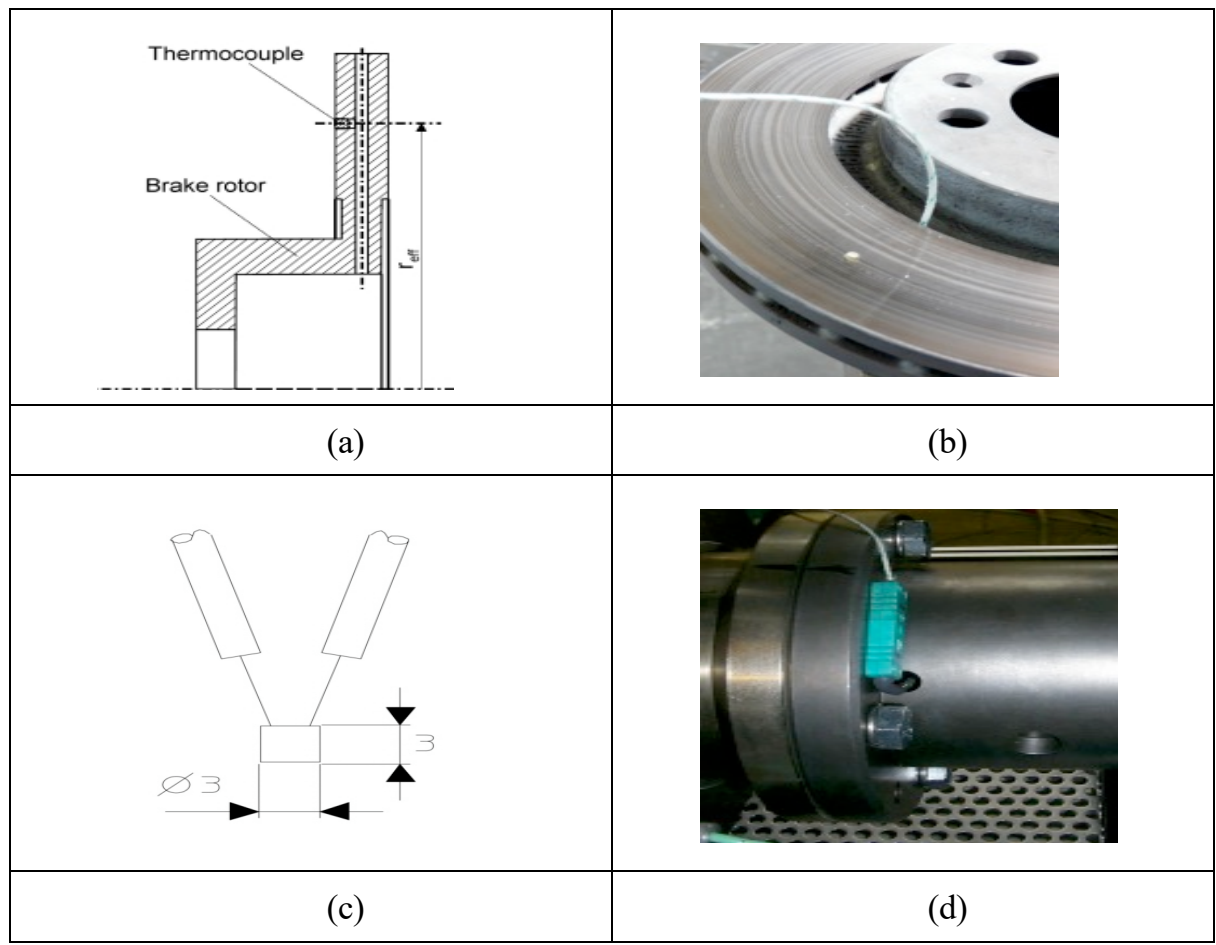

Figure 2. Temperature measuring with embedded thermocouple as per VDA285-1.

The tests were performed by rotating the wheel at a constant speed approximately equal to the vehicle speed of $108 \mathrm{~km} / \mathrm{h}$. Progressive braking load was applied, and the temperatures were recorded at very short intervals of 0.01 seconds. The method started with the disc heating up to a temperature of about $345^{\circ} \mathrm{C}$, at which point the braking load was released.

\section{RESULTS AND DISCUSSION OF CFD ANALYSIS}

\section{Evaluation of the heat exchange coefficient (h)}

Figs. 3(a)-(b) show the evolution of the heat transfer coefficient (h) at each surface of the full and ventilated disc, as a function of time. We used these two graphs later to predict the three-dimensional distribution of the two brake discs. It can be said that the values of the convective heat exchange coefficient (h) vary according to the 
geometric design of the disc, whether it is full or ventilated, and it is quite rational that the aeration generates the decrease of the maximum temperatures at the walls.

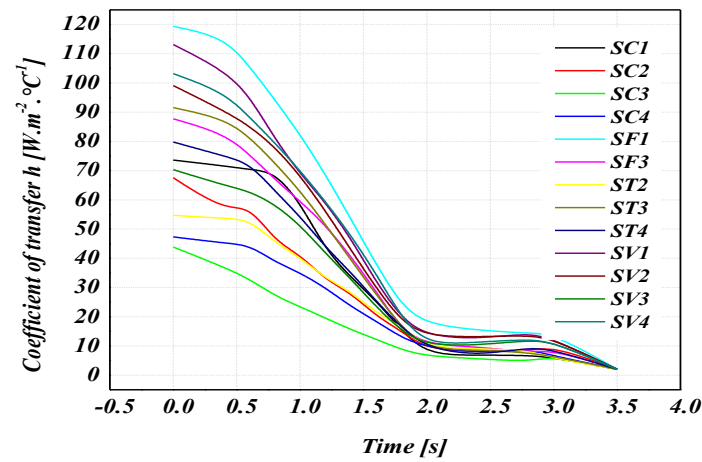

(a)

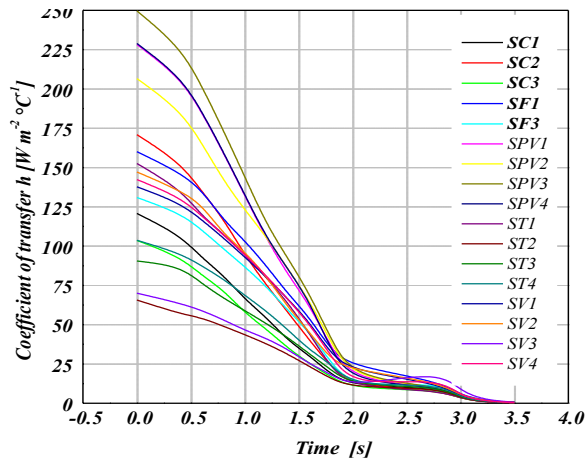

(b)

Figure 3. Heat transfer coefficient (h) versus time at different disc surfaces at material FG15 in the transient thermal case for (a) full disc faces and (b) ventilated disc.

\section{RESULTS AND DISCUSSION OF FEM ANALYSIS}

\section{Model validation against experimental data}

The analysis in this work is compared to available literatures to ensure the reliability of the results. Figure 4 shows the time variation of the observed disc temperature against the values from (Stephens, 2006). Figure 4 shows that the temperature results from both the thermocouple and the finite element software ANSYS 11.0 of the ventilated disc brake made of material FG15 are very similar. It can also be concluded that the transient thermal simulation of the ventilated disc, performed by the finite element method, gives us a good correlation with the thermocouple measurements.

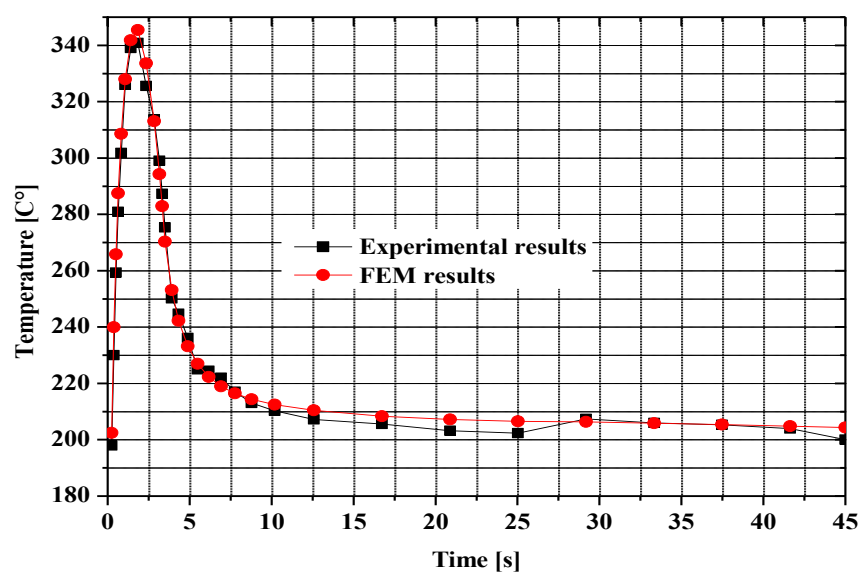

Figure 4. Validation of the FEM model against experiments by Stephens (2006). 


\section{Results of the Disc Temperature}

The transient thermal analysis of the two discs, full and ventilated brake discs, was performed using finite element (FE) software. The calculation does not last very long, which is a positive point. The results of the temperature distribution (3D) for the three materials, namely, the gray cast iron FG25AL, FG20, and FG15, are provided in Figure 5. It should be understood that the material having lower thermal conductivity thus generates important thermal gradients and consequently increases in the surface temperature of the brake disc. To make the choice of material and to know if it is profitable, we tested the one that cools better, and it is necessary to remember that one wants to have a material that does not preserve heat. From the results provided by this simulation, it can be seen that the ventilated discs are made of the materials FG20 and FG25AL, respectively, having temperatures reaching 351.5 and $380.2^{\circ} \mathrm{C}$, which in turn are greater than those of the ventilated disc of material FG15 having a maximum temperature of $345.4{ }^{\circ} \mathrm{C}$ as indicated in Figure 6 . It can thus be concluded that the most suitable material in this case for the brake discs is the gray cast iron FG15, which presents the better thermal performance.

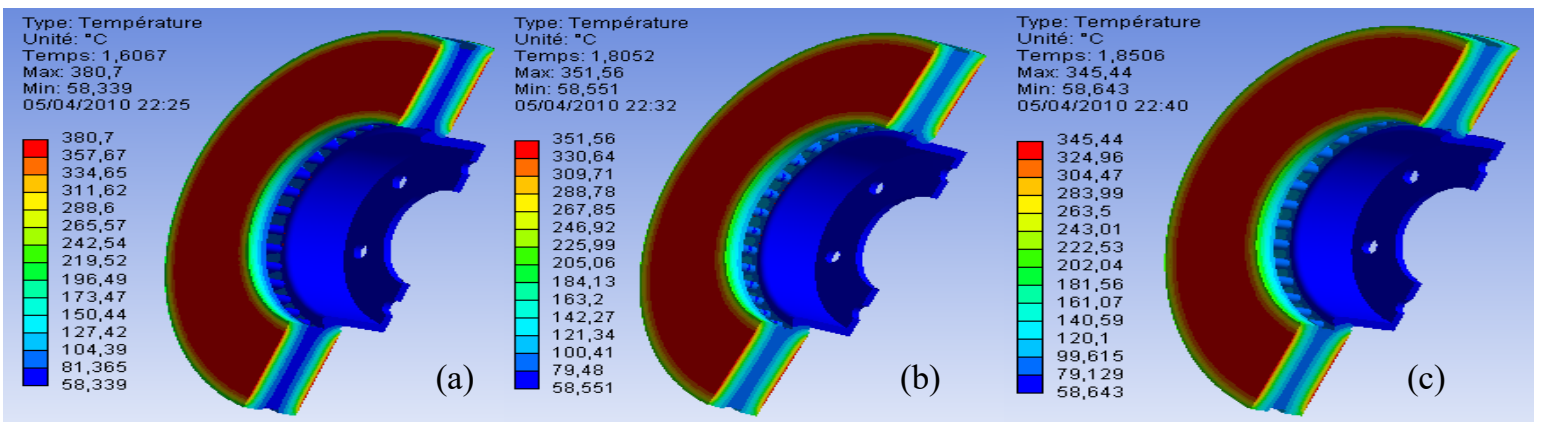

Figure 5. Temperature plot of ventilated discs for three materials gray cast iron

(a) FG25 AL, (b) FG20, and (c) FG15.

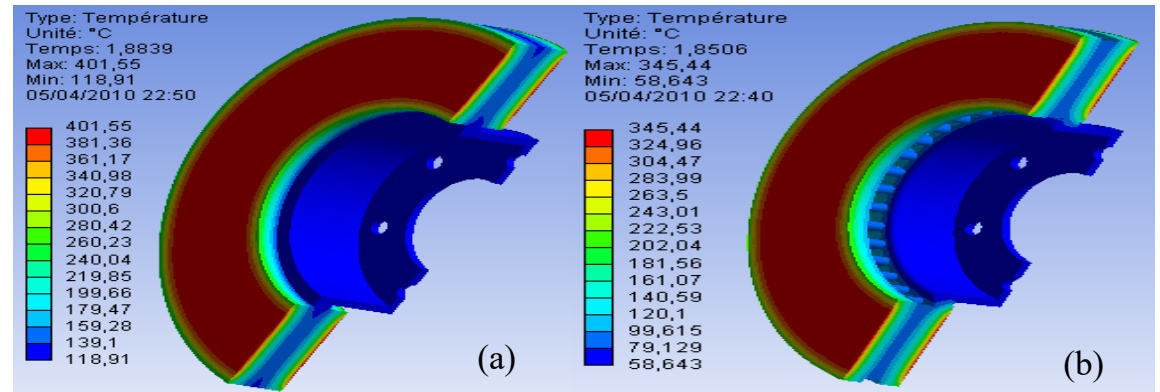

Figure 6. Temperature plot on disc brake of the same material (FG15):

(a) full disc, (b) ventilated disc.

\section{COUPLED THERMO-MECHANICAL ANALYSIS}

\section{Calculation of Hydraulic Pressure}

The rotor force for a typical vehicle can be calculated as follows (Mackin et al.,2002): 
$F_{\text {disc }}=\frac{(30 \%) \frac{1}{2} m v_{0}^{2}}{2 \frac{R_{\text {rotor }}}{R_{\text {tire }}}\left(v_{0} t_{\text {stop }}-\frac{1}{2}\left\{\frac{v_{0}}{t_{\text {stop }}}\right\} t_{\text {stop }}^{2}\right)}=1047.36[\mathrm{~N}]$

The angular velocity of the rotor can be evaluated as follows:

$\omega=\frac{v_{0}}{R_{\text {tire }}}=157.89 \mathrm{rad} / \mathrm{s}$

The value of the hydraulic pressure $\mathrm{P}$ is obtained from the following form (Oder et al., 2009):

$P=\frac{F_{\text {disc }}}{A_{c} \mu}=1[M P a]$

where $\mu$ is the friction coefficient, and $A_{c}$ is the surface of the brake pad in contact with the brake disc.

\section{FE Model and Boundary Conditions}

Figures 7 (a) and (b) show the boundary conditions imposed on FE model, consisting of brake disc and two brake pads in dry contact in the case of pressure exerted on one side of the pad and that of double pressure on both sides of the pad. As we have done the thermal analysis, the conditions to be taken into account are those which will influence the thermal phenomena such as the ambient temperature, which is the initial temperature of disc $20^{\circ} \mathrm{C}$, the thermal flow, and that of convection imposed on all the surfaces of the brake disc, while for the two brake pads (Abu Bakar et al.,2010), the convective heat exchange coefficient (h) is of value $5 \mathrm{~W} / \mathrm{m} 2 .{ }^{\circ} \mathrm{C}$ is applied on their outer surfaces on both sides (Figure8). For structural boundary conditions, we know that the brake disc is fixed to the mounting holes, thus requiring fixed support on these holes taking into account its rotational speed (Coudeyras,2009): $\omega=157.89 \mathrm{rad} / \mathrm{sec}$. The internal disc diameter is sustained at fixed support for both radial directions, while the tangential direction is left free in this simulation. The structural boundary conditions applied to pads are also introduced. We imposed pressure of $1 \mathrm{MPa}$ on the piston pad while maintaining fixed support on the finger pad, while on the contact surface, the pad is assembled on its edges at the perpendicular plane. The friction between the two disc brake pad parts is defined by a coefficient equal to 0.2 .

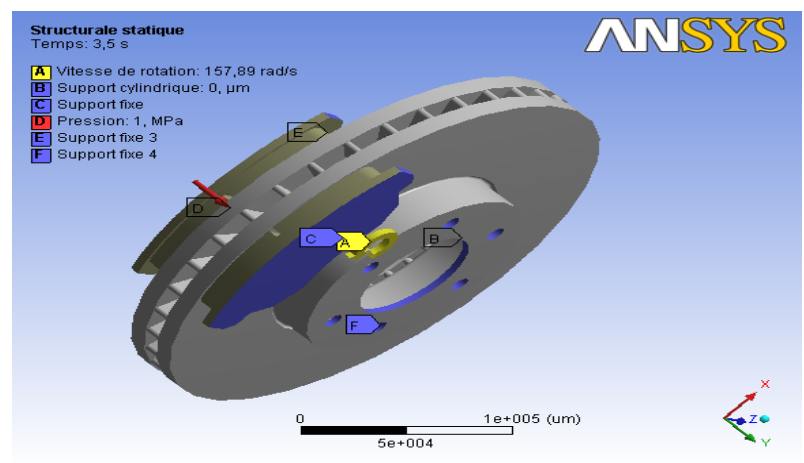

(a) One piston 


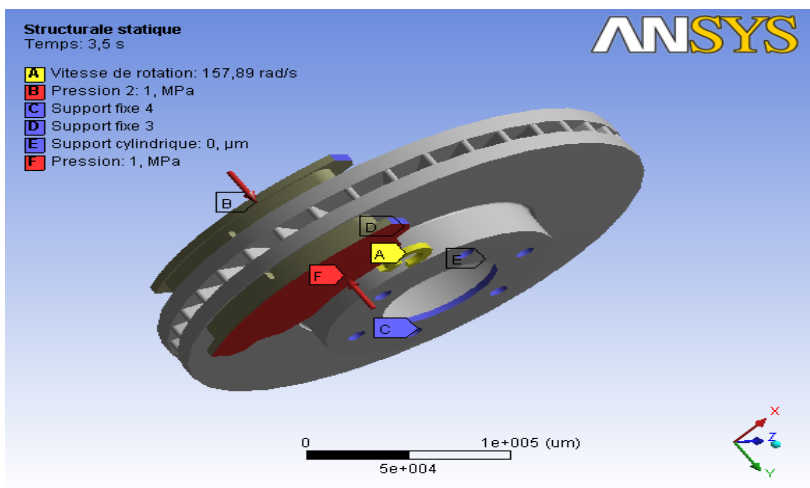

(b) Two pistons

Figure 7. Loading conditions for disc brake assembly.

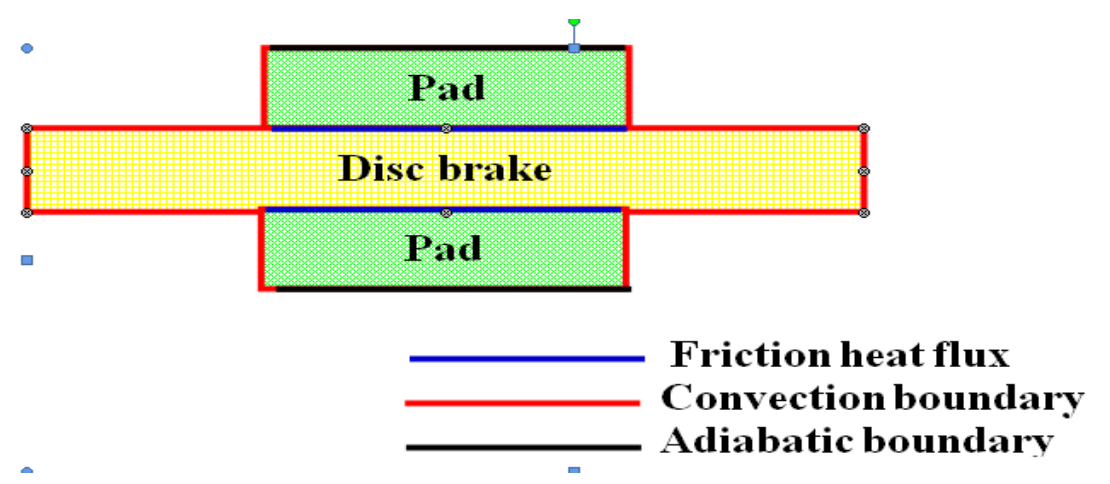

Figure 8. Thermal boundary condition applied to the model.

\section{Geometry and mesh}

A three-dimensional mesh of ventilated disc was developed with the ANSYS software (Figure 9). The total number of nodes is 185901, while the total number of elements is 113367 .

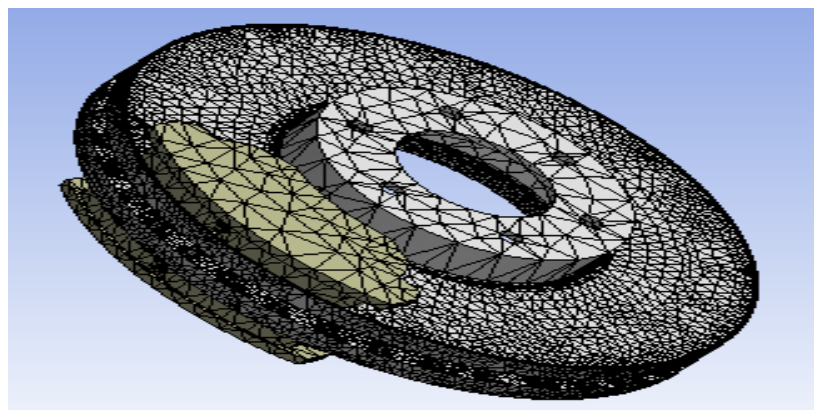

Figure 9. Meshed model of the disc brake assembly. 


\section{Thermal Distortion}

Figure 10 shows the maps of the total deformation of the whole model (disc brake pads) evaluated at times $\mathrm{t}=$ $1.7271 \mathrm{~s}, 3.5 \mathrm{~s}, 30 \mathrm{~s}$, and $45 \mathrm{~s}$. According to this figure, the maximum total deformation recorded at time $\mathrm{t}=3.5 \mathrm{~s}$ is of the order $284.55 \mu \mathrm{m}$, where it coincides with the braking moment. It is obvious that strong distribution amplifies with time as well on the tracks of friction of the disc and its outer ring that its fins of cooling. Indeed, at the beginning of the braking, relatively homogeneous, hot bands appear on the friction tracks of the disc. During braking, this hot strip with hot spots gradually migrates to the inner radius. Hot spots intensify to form stationary macroscopic hot spots at the inner radius. At the end of the braking, the intensity decreases, and the surface gradients homogenize. The migration of the locations is explained by the difference in expansion between the track of the disc and its rear face, leading to "umbrella" deformed disc during warm-up. Deformation of the structure, therefore, has a preponderant role in the migration of thermal locations.

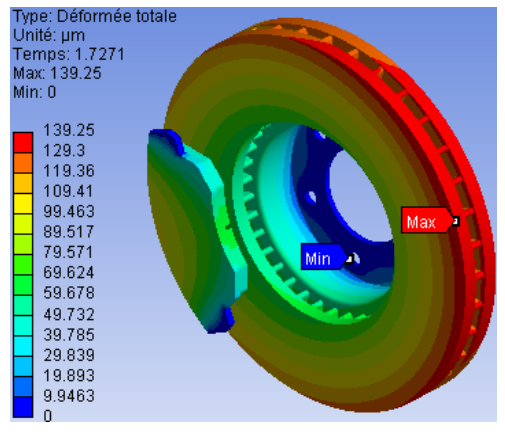

(a) $\mathrm{t}=1.7271$

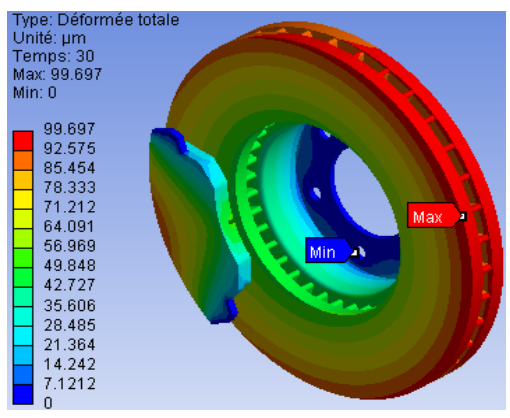

(c) $\mathrm{t}=30 \mathrm{~s}$

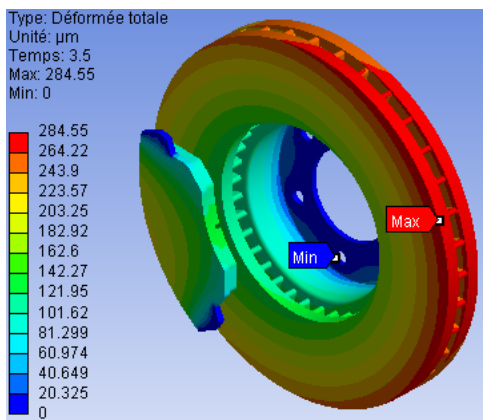

(b) $\mathrm{t}=3.5 \mathrm{~s}$

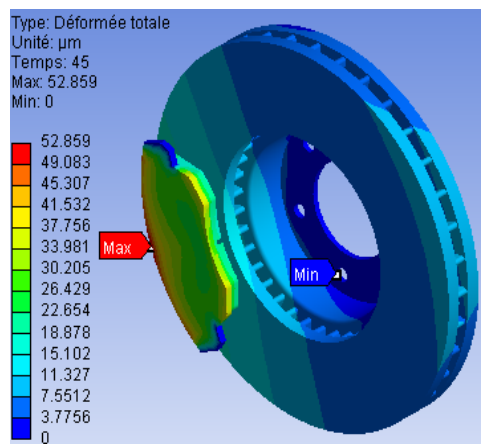

(d) $\mathrm{t}=45 \mathrm{~s}$

Figure 10. Total deformation of the disc pad model.

\section{Von Mises stress distribution}

The model provides access to Von Mises stress distribution mapping at the start of braking (Figure 11) and after cooling the sector to ambient temperature. The distribution is well noted here in an order ranging from 0 to 495.56 MPa. The great value recorded during this modeling in thermomechanical coupling is significant when compared to mechanical dry contact analysis under the same braking conditions. According to the established conclusion, the Von Mises stresses are maximum in the outer band at the level of the brake disc bowl at the instant $3.5 \mathrm{~s}$, corresponding to the moment when the thermal gradient in the thickness of the track is the most important. 
Indeed, the brake disc is fixed to the hub by bolts in order to prevent its movement and as soon as it starts to rotate, torsion and shear stresses have just been produced at the level of its bowl, which generates automatically stress concentrations around its fixing holes. The disc bowl thus risks mechanical rupture under repetitions of these undesirable effects during the braking process. The general evolution of the stresses in the disc during the brakingcooling cycle agrees with the phenomena described in the previous literature searches.

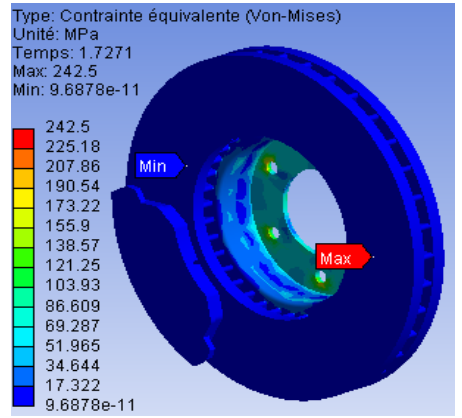

(a) $\mathrm{t}=1.7271 \mathrm{~s}$

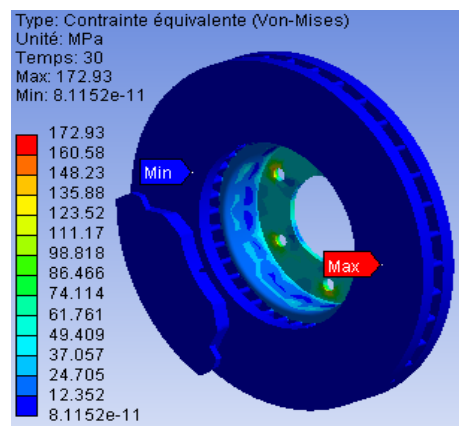

(c) $\mathrm{t}=30 \mathrm{~s}$

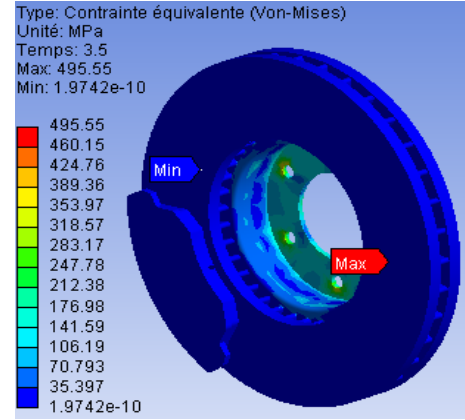

(b) $\mathrm{t}=3.5 \mathrm{~s}$

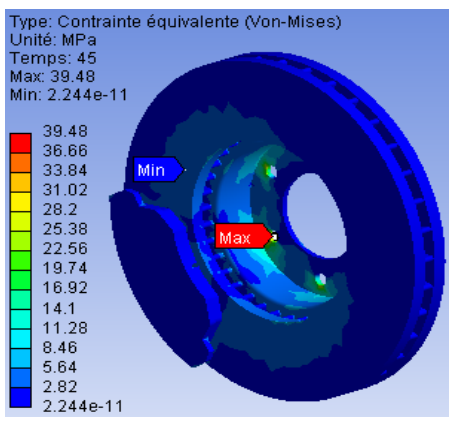

(d) $\mathrm{t}=45 \mathrm{~s}$

Figure 11. von Mises equivalent stress obtained step by step.

\section{Contact Pressure Distribution}

Figure 12 shows the mapping of the contact pressure at the friction interface between the internal brake pads and the brake disc with various simulation times. In these, the maximum contact pressures evaluated are of the order $3.3477 \mathrm{MPa}$ at the instant when the rotational speed is zero $t=3.5 \mathrm{~s}$. It can also be seen that this maximum value is in the leading edges of the pads towards the trailing edge by friction. Moreover, the distribution of the contact pressure is quite symmetrical with respect to the groove of the brake pads. In the thermomechanical coupling that we carried out here, it is clear that the contact pressures are not negligible and can reach locally very high values of the order GPa. The plastic flow observed in the sliding direction attests well to the severity of the friction forces, so very high contact pressure. 


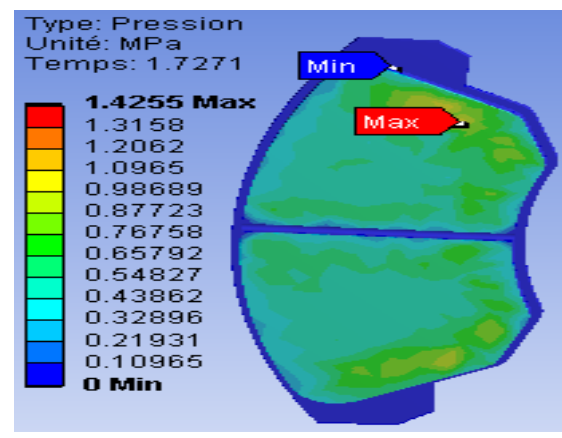

(a) $\mathrm{t}=1.7271 \mathrm{~s}$

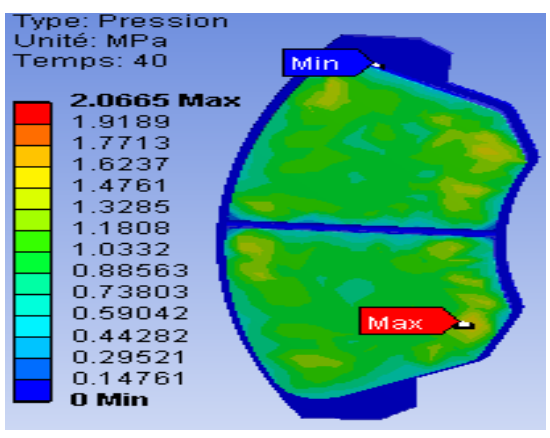

(c) $t=40 s$

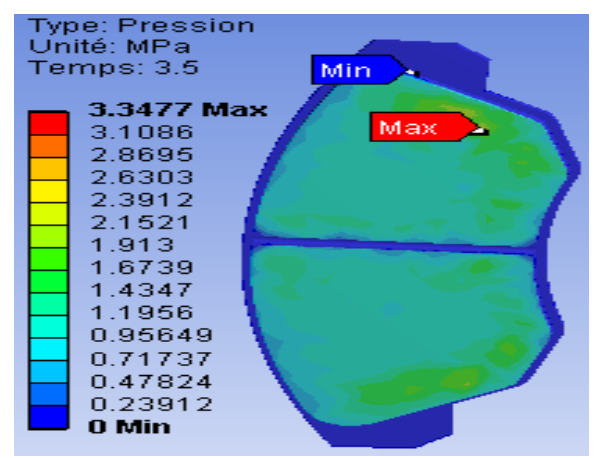

(b) $\mathrm{t}=3.5 \mathrm{~s}$

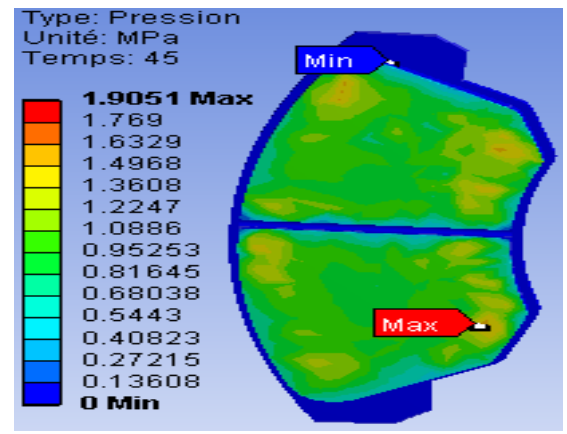

(d) $\mathrm{t}=45 \mathrm{~s}$

Figure 12. Contact pressure distribution in the inner pad.

\section{Von Mises Stress at the Inner Pad}

In order to study the influence of the groove of the brake pads as well as loading modes applied to the pistons (single-pressure and double-pressure), we solve the model and ask for the equivalent Von Mises stress of three different designs. Brake pads in this case, brake pad with center groove, are subject to the single double piston. We obtain the following visuals that are grouped in Figures 13 (a) to (c). It can be seen that almost all the contact pads of the brake pads are dressed in dark blue color meaning low stresses at the beginning of the braking moment $(\mathrm{t}=$ $1.7 \mathrm{~s}$ ). Nevertheless, from the moment of the end of braking $\mathrm{t}=45 \mathrm{~s}$, the scale of von Mises stress becomes more important whose vision of the colors becomes practically blue ocean and whose distribution is well noticed on the three conceptions. It can be concluded that the existence of the groove in the brake pad and the presence of a mechanical double piston loading have a positive influence on the distribution of brake pad stresses. 

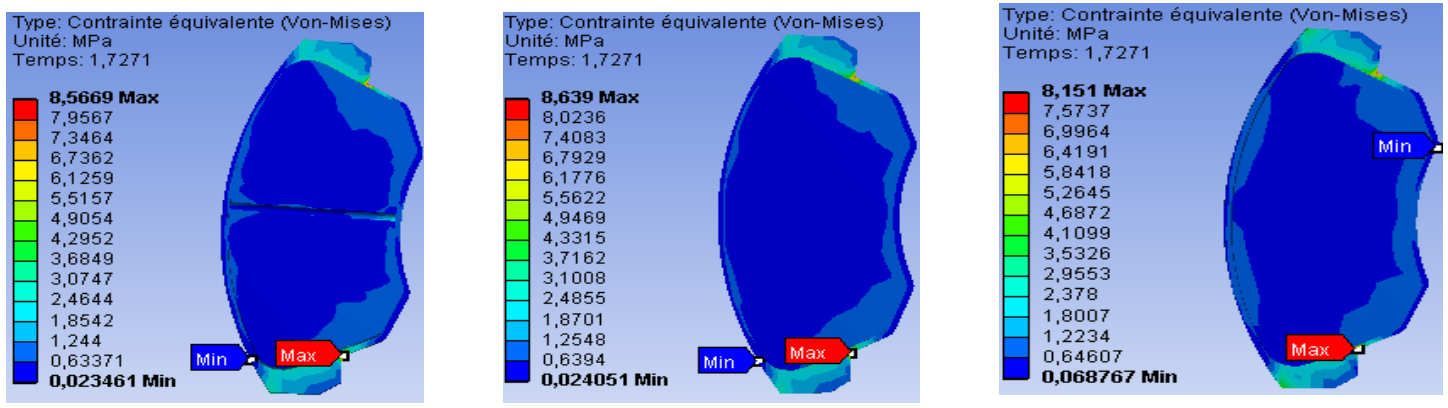

-a- : at time $t=1.7 \mathrm{~s}$
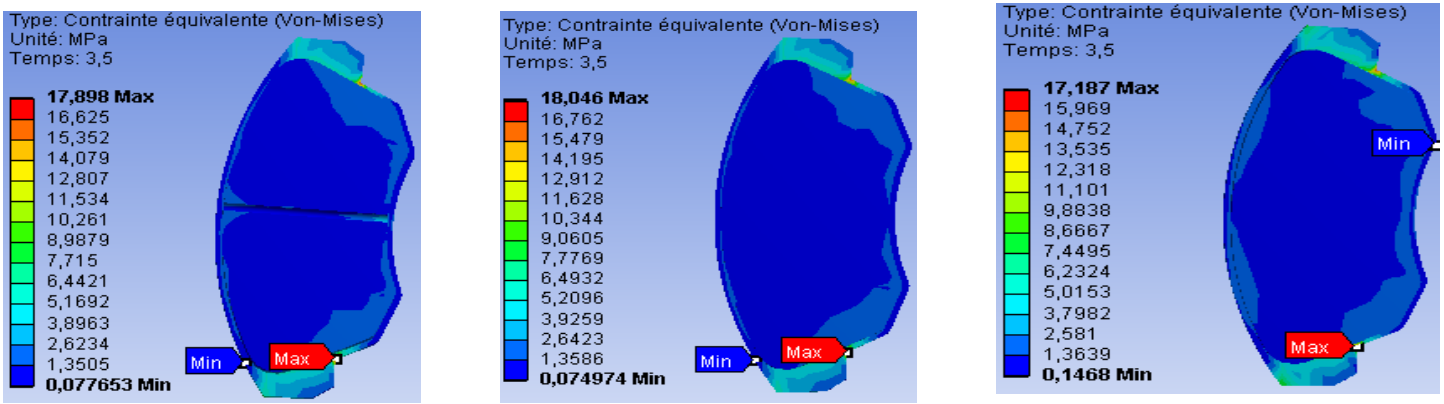

-b- : at time $t=3.5 \mathrm{~s}$
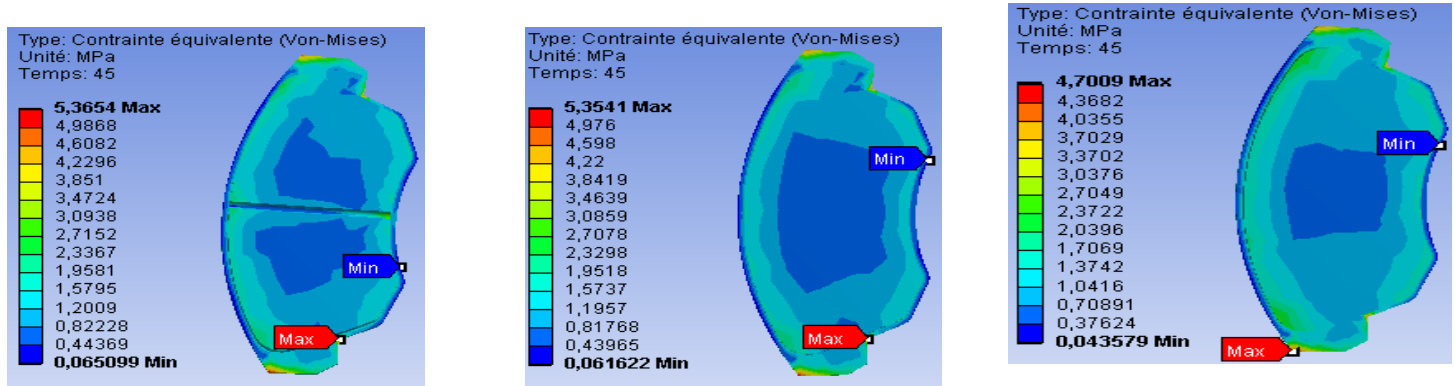

-c- : at time $t=45 \mathrm{~s}$

Figure 13. Distribution of Von Mises stress at different braking time: Single piston with pad center-groove (left), Single piston without groove (center) and Double piston without pad groove (right).

\section{CONCLUSION}

In the transport sector, braking is a major problem. It is a question of obtaining this safety equipment systematic reliability with acceptable cost, whereas the phenomena that are attached to it are complex. In general, from the thermal point of view , the braking system is considered to be composed of only three elements: the disc in motion at variable speed, on which are rubbed the two pads that are subjected to pressure evolving over time. The phenomenon of induced friction generates dissipation of thermal power at the interface and causes a sharp increase in temperature that may deteriorate the equipment. The temperature level reached is directly related to the way in which the heat is transferred into its immediate environment, that is to say, the disc and the two pads. In this paper, we presented complex modeling of convection-driven brake discs in order to predict the heat transfer coefficients (h) during the aerodynamic conditions of the braking stage by using the software adapted in elements. ANSYS 
CFX finishes. Moreover, important results from this numerical computation were used to study the transient thermal scenario during the braking, which was executed on the two full and ventilated brake discs to which one visualized the temperature reached, thanks to the software ANSYS Workbench. The main objective of this study is to unveil the system design impact of ventilation in the cooling mechanism of the brake discs to ensure famous thermal endurance that guarantees a longer life. The results were also validated using the temperature-time profile from both the simulated and experimental results, in which the two results were found to be in good agreement. The literature for ventilated brake disc with gray cast iron FG15 also shows a good agreement with the results from the literature. In this research, we simulated the disc brake pad assembly model by employing a coupled thermomechanical approach, whose results we obtained:

- At the level of outer radius and crown of the disc, strong ditty occurs

- In pad without groove and subjected to double pressure, the stresses intensify significantly during braking.

- The temperature has a significant effect on the thermomechanical behavior of the braking system. Thus, in the presence of a thermal effect, the contact pressure of pad and overall deformation of the brake disc are quite considerably prominent.

However, it seems to us that several thermomechanical turns can and should be visited in more detail in the topic of braking, essentially for more quantitative estimation of damage in life expectancy approach, which are defined in perspective. Additional thermomechanical speculations could be taken into consideration to better comment on the effect of migration of thermal locations.

\section{CONFLICTS OF INTEREST}

The authors declare that there are no conflicts of interest.

\section{REFERENCES}

Abu Bakar, A.R., Ouyang, H., Khai, L.C., \& Abdullah, M.S. 2010. Thermal analysis of a disc brake model considering a real brake pad surface and wear. International Journal of Vehicle Structures and Systems 2(1): 20-27.

Belhocine, A. \& Ghazaly, N.M.2016. Effects of Young's modulus on disc brake squeal using finite element analysis. International Journal of Acoustics and Vibration 31(3): 292-300.

Choi, J. H. \& Lee, I. 2003. Transient thermoelastic analysis of disk brakes in frictional contact. Journal of Thermal Stresses 26(3): 223-244.

Choi, J. H. \& Lee, I. 2004. Finite element analysis of transient thermoelastic behaviors in disk brakes. Wear 257(1-2): 47-58.

Dufrénoy, P. \& Weichert, D.1995. Prediction of railway disc brake temperatures taking the bearing surface variations into account. Proceedings of the Institution of Mechanical Engineers, Part F: Journal of Rail and Rapid Transit 209(2):67-76.

Duzgun, M. 2012. Investigation of thermo-structural behaviors of different ventilation applications on brake discs. Journal of Mechanical Science and Technology 26(1): 235-240.

Eyercioglu, $O$ \& Yılmaz, N.F.2021. A simplified formula for determination of relative pressure in the precision forging of spur gears. Journal of Engineering Research 9 (2): 234-248. 
Han, M.J., Lee, C.H., Park, T.W., \& Lee, S.P. 2018. Low and high cycle fatigue of automotive brake discs using coupled thermo-mechanical finite element analysis under thermal loading. Journal of Mechanical Science and Technology 32 (12): 5777-5784.

Han, M. J., Lee, C.H., Park, T.W., Park, J. M., \& Son, S. M. 2017. Coupled thermo-mechanical analysis and shape optimization for reducing uneven wear of brake pads, International Journal of Automotive Technology 18(6): 1027-1035.

Hwang, P. \& Wu, X. 2010. Investigation of temperature and thermal stress in ventilated disc brake based on $3 \mathrm{~d}$ thermo-mechanical coupling model. Journal of Mechanical Science and Technology 24(1) : 81-84.

Ishak, M.R., Abu Bakar, A.R., Belhocine, A., Taib, J.M., \& Wan Omar, W.Z. 2018. Brake torque analysis of fully mechanical parking brake system. Theoretical and experimental approach, Ingenieria Investigacion y Tecnologia 19(1): 37-49.

Kao, T., Richmond, J., \& Douarre , A. 2000. Brake disc hot spoting and thermal judder: an experimental and finite element study. International Journal of Vehicle Design 23(3): 276-296.

Li , Q.M \& Liu, E.L. 2018. Numerical analysis of wetting-induced deformation of rock fill dams, Journal of Engineering -Research. 5 (6) : 1-14.

Mackin, T.J., Noe, S.C., Ball, K.J., Bedell, B.C., Bim-Merle, D.P., Bingaman, M.C., Bomleny, D.M., Chemlir, G.J., Clayton, D.B. \& Evans, H.A.2002. Thermal cracking in disc brakes. Engineering Failure Analysis 9: 63-76.

Noufid, A \& Belattar, S.2019. Infrared thermography and finite element method applied to the detection of internal defects in reinforced concrete slabs, Journal of Engineering Research 7 (2) : 125-142.

Oder, G., Reibenschuh, M., Lerher, T., Šraml, M., Šamec, B. \&Potrč, I .2009. Thermal and stress analysis of brake discs in railway vehicles. Advanced Engineering 3(1): 95-102.

Reimpel, J.,1998. Braking Technology, Vogel Verlag, Würzburg.

Sen ,H., Yilmaz, S \& Yildiz, R.A.2020. Springback behavior of DP600 Steel: An implicit

finite element simulation. Journal of Engineering Research 8(2) :252-264.

Sivandi-Pour, A., Farsangi, E.N., \& Takewaki, I.2020. Estimation of vibration frequency of structural floors using combined artificial intelligence and finite element simulation. Journal of Engineering Research 8 (3) : $1-16$.

Stephens, A.2006. Aerodynamic Cooling of Automotive Disc Brakes, Master's thesis, School of Aerospace, Mechanical \& Manufacturing Engineering, RMIT University, March.

Wang, G \& Ding, Y.2020. The effects of uniform temperature and bolts fracture on the behaviour of high strength bolted frictional steel connection in Dashegnguan Railway Bridge, Journal of Engineering Research 8 (1) : 107-127.

Yildiz, Y. \& Duzgun, M.2010. Stress analysis of ventilated brake discs using the finite element method. International Journal of Automotive Technology 11(1): 133-138. 